\title{
Assessing health-related quality of life in children with spina bifida
}

\author{
Brandon G. Rocque, MD, MS, ${ }^{1}$ E. Ralee' Bishop, BS, ${ }^{1}$ Mallory A. Scogin, MD, ${ }^{1}$ \\ Betsy D. Hopson, MSHA, ${ }^{1}$ Anastasia A. Arynchyna, MPH, ${ }^{1}$ Christina J. Boddiford, MPH, ${ }^{1}$ \\ Chevis N. Shannon, MBA, DrPH, ${ }^{2}$ and Jeffrey P. Blount, MD ${ }^{1}$
}

\begin{abstract}
${ }^{1}$ Pediatric Neurosurgery, Department of Neurosurgery, University of Alabama at Birmingham, Alabama; and 2Department of Neurosurgery, Vanderbilt University, Nashville, Tennessee
\end{abstract}

\begin{abstract}
OBJECT The purpose of this study is to explore various aspects of health-related quality of life (HRQOL) in children with spinal dysraphism.

METHODS The authors enrolled a prospective cohort of 159 patients from the multidisciplinary spina bifida clinic. Surveys were distributed to caregivers of patients with spina bifida who were 5 years old and older. Data were collected using the Health Utilities Index Mark 3 focusing on vision, speech, hearing, dexterity, ambulation, cognition, emotions, and pain. Each participant received an overall HRQOL utility score and individual domain subscores. These were correlated with demographic and treatment variables. Analysis was done using SPSS statistics (version 21).
\end{abstract}

RESULTS There were 125 patients with myelomeningocele, 25 with lipomyelomeningocele, and 9 with other dysraphisms. Among patients with myelomeningocele, 107 (86\%) had CSF shunts in place, 14 (11\%) had undergone Chiari malformation Type II decompression, 59 (47\%) were community ambulators, and 45 (36\%) were nonambulatory.

Patients with myelomeningocele had significantly lower overall HRQOL scores than patients with closed spinal dysraphism. Among patients with myelomeningocele, younger patients had higher HRQOL scores. Patients with impaired bowel continence had lower overall HRQOL scores. History of a ventriculoperitoneal shunt was associated with worse HRQOL (overall score, ambulation, and cognition subscores). History of Chiari malformation Type II decompression was associated with worse overall, speech, and cognition scores. Patients who could ambulate in the community had higher overall and ambulation scores. A history of tethered cord release was correlated with lower pain subscore. No association was found between sex, race, insurance type, or bladder continence and HRQOL.

CONCLUSIONS Patients with myelomeningocele have significantly lower HRQOL scores than those with other spinal dysraphisms. History of shunt treatment and Chiari decompression correlate with lower HRQOL scores.

http://thejns.org/doi/abs/10.3171/2014.10.PEDS1441

KEY WORDS spina bifida; myelomeningocele; quality of life; hydrocephalus; shunt; lipomyelomeningocele; congenital

$\mathrm{W}$ HILE the incidence of spina bifida has decreased since the introduction of folic acid supplementation in the 1990s, it remains the most common permanently disabling birth defect. ${ }^{4}$ Recent estimates indicate that 1500 children are born with spina bifida in the United States each year. ${ }^{16}$ For these children, medical and surgical advances have extended their life expectancy, with important clinical repercussions. The 1-year survival rate of infants born with spina bifida now exceeds $92 \%$, and almost $75 \%$ reach adulthood., ${ }^{2,3}$ Spina bifida patients continue to face a spectrum of medical, physical, and neurocognitive challenges, including sensory and motor deficits, decreased functional mobility, bowel and bladder control issues, muscle weakness, skeletal deformities, cognitive deficits, obesity, and unique allergic reactions. ${ }^{19}$

A recent focus on patient-centered health care aims to improve efficacy, capacity, quality, cost-effectiveness, communication, and cooperation in the treatment of patients. Furthermore, an integrated, multidisciplinary approach to health care has been associated with better psy-

ABBREVIATIONS CM-II = Chiari malformation Type II; COA = Children's of Alabama; CPC = choroid plexus cauterization; ETV = endoscopic third ventriculostomy; HRQOL = health-related QOL; HUI3 = Health Utilities Index Mark 3; QOL = quality of life; VP = ventriculoperitoneal.

SUBMITTED March 9, 2014. ACCEPTED October 13, 2014.

INCLUDE WHEN CITING Published online November 21, 2014; DOI: 10.3171/2014.10.PEDS1441.

DISCLOSURE The authors report no conflict of interest concerning the materials or methods used in this study or the findings specified in this paper. Health Utilities Inc. provided a grant to support use of the HUl-3 instrument for this study. 
chosocial outcomes in patients with spina bifida. ${ }^{20,22}$ As such, the importance of studying health-related quality of life (HRQOL) in addition to traditional outcome measures in the spina bifida population is being increasingly recognized. ${ }^{18} \mathrm{HRQOL}$ focuses on how each patient assesses the influence of a chronic health issue on his/her physical and psychosocial functioning. ${ }^{17,21}$

The goal of the present study was to characterize the quality of life (QOL) of pediatric patients with spina bifida who were seen at a multidisciplinary, comprehensive outpatient clinic within a large medical center. In addition to serving as a vital part of the ongoing assessment of spina bifida care at Children's of Alabama (COA), these results will allow analysis of factors that influence HRQOL and will aid in the determination of whether a correlation exists between various disease and/or personal characteristics and HRQOL scores.

\section{Methods \\ Research Setting}

The study population consisted of patients attending a multidisciplinary pediatric spina bifida clinic at COA from March 2012 to March 2013. The population of the clinic included patients between the ages of 0 and 21 years with a diagnosis of myelomeningocele, lipomyelomeningocele, sacral agenesis, dermal sinus tract, split cord malformation, and other spinal dysraphisms. Ethics consideration and approval were obtained from the institutional review board of the University of Alabama at Birmingham prior to the initiation of this project.

\section{Study Design and Procedures}

Over the course of 1 year, all English-speaking parents or guardians of patients 5 years old and older attending the multidisciplinary clinic at COA were invited to participate in this study on behalf of their children. Qualifying families were approached during their clinic visit and were given a letter detailing the purpose and procedures of this project, and they received the survey. Qualifying children were encouraged to complete the survey themselves if possible but were allowed to have their parents or guardians complete the form as a proxy if needed. The survey was completed by patients and/or their proxies in the privacy of the patient's examination room, and completed surveys were collected by research staff prior to the patient's departure from clinic.

\section{Measures}

The Health Utilities Index Mark 3 (HUI3) is a 15-question survey that evaluates 8 independent attributes of health: vision, hearing, speech, cognition, emotion, pain, ambulation, and dexterity. A score for each attribute is assessed based on the participant's choice of 4-5 responses, and normative scores are based upon population preferences for levels of optimal health across the 8 domains. Preference scores range from a value representing death (0.00) to a value representing perfect health (1.00). The aggregate scores have a mathematical minimum of -0.341 and a maximum of $1.0 .{ }^{25}$ Using the HUI3-defined scoring algorithms, single-attribute scores can then be compiled to determine an overall multiattribute score. Multiattribute scores, which encompass all domains concurrently and account for interaction between attributes, are calculated to derive an estimation of the participant's overall HRQOL. HUI measures are validated generic questionnaires used extensively in both healthy and chronically ill pediatric and adult populations to describe health states and are designed for both self- and proxy administration. ${ }^{7}$ Health Utilities Inc. provided a grant to support the use of the HUI3 metric for this study.

\section{Statistical Analyses}

Results from QOL surveys are nonparametric variables, since results tend to cluster around the maximum value (1.00 in the case of HUI3). Because these data are not normally distributed, nonparametric statistical tools are required. For comparison of QOL scores between 2 categories, the Mann-Whitney U-test was used. For comparison of QOL scores between more than 2 categories, the Kruskal-Wallis test was used. Correlation between continuous variables was assessed using the Spearman rho correlation coefficient.

Care was taken to control for potential confounding variables where appropriate. When a continuous variable, such as age, was a potential confounder for a categorical variable, we performed 1-way between-groups ANCOVA. When a categorical variable was a potential confounder for another categorical variable, we performed 2-way between-group ANOVA. Because of the nonnormal distribution of QOL variables, a cutoff of $\mathrm{p}<0.01$ was used to define statistical significance in circumstances in which 2-way ANOVA was used.

\section{Results}

Surveys were distributed to 283 patients who met inclusion criteria. Of these, 159 patients or their proxy $(56 \%)$ completed the HUI3 survey. The underlying diagnosis was myelomeningocele in 125 patients, lipomyelomeningocele in 25 , meningocele in 5, filum terminale-related pathology in 3 , and sacral agenesis in 1 patient. Patients varied in age from 5 to 20 years, with a mean of 12.6 years. Ninetyone patients $(57 \%)$ were female; $116(73 \%)$ were white, 32 $(20 \%)$ were black, and $4(2.5 \%)$ were Hispanic. Seventeen patients $(11 \%)$ completed the survey themselves, and 142 caregivers $(89 \%)$ completed the rest. Eighty-three patients had health insurance through a commercial preferred provider organization (52\%), 61 had Medicaid (38\%), and 15 had a combination of insurance providers (9.4\%).

Among patients with myelomeningocele, 107 (86\%) had CSF shunts in place and $14(11 \%)$ had undergone Chiari malformation Type II (CM-II) decompression. Fiftynine percent of patients had undergone at least 1 shunt revision (range $0-15$, mean 1.84 , median 1 ). Only patients with myelomeningocele had undergone shunting or CM-II decompression. Fifty-nine (47\%) of the myelomeningocele patients were able to ambulate in the community. Twentynine myelomeningocele patients $(23 \%)$ reported bowel continence and 36 (29\%) reported bladder continence. Thirty-seven patients $(30 \%)$ had undergone a tethered cord release. 


\section{Diagnosis, Demographics, and QOL}

In patients with open myelomeningocele, multiattribute QOL scores were significantly lower than those in patients with closed neural tube defects for ambulation and cognition (ambulation mean score 0.74 vs $0.94, \mathrm{p}<0.001$; cognition mean score 0.92 vs $0.96, p=0.039$ ). Overall HRQOL score was also lower for patients with myelomeningocele than for those with closed dysraphism (mean score 0.51 vs 0.77, p < 0.001; Fig. 1).

No difference in any QOL measure was seen for scores from patients who completed the survey themselves compared with those whose survey was completed by a caregiver, or in male versus female patients, or white versus nonwhite patients. Patients with commercial health insurance had significantly higher scores for ambulation and overall QOL than those with Medicaid or a combination of insurance carriers (ambulation, $\mathrm{p}=0.033$; overall, $\mathrm{p}=$ $0.027)$. However, $72 \%$ of patients with commercial health insurance had an underlying diagnosis of myelomeningocele compared with $90 \%$ of Medicaid or combination coverage patients $(\mathrm{p}<0.001$, chi-square test). Controlling for this difference in diagnosis eliminated the difference in QOL score observed between patients with commercial insurance and others.

Younger age correlated with higher QOL scores in multiple domains (vision [rho $=-0.27, p=0.001$ ], emotion [rho $=-0.329, \mathrm{p}<0.001]$, pain [rho $=-0.222, \mathrm{p}=0.005]$, and ambulation [rho $=-0.178, \mathrm{p}=0.027]$ ) and with higher overall QOL (rho $=-0.211, \mathrm{p}=0.009$ ). This correlation was roughly linear, with no drop-off noted above a particular age.

\section{Bowel and Bladder Continence}

Thirty-two percent of patients had intact bowel continence, and 35\% had intact bladder continence (defined as absence of accidents with or without interventions or management plans). Overall QOL score and ambulation QOL

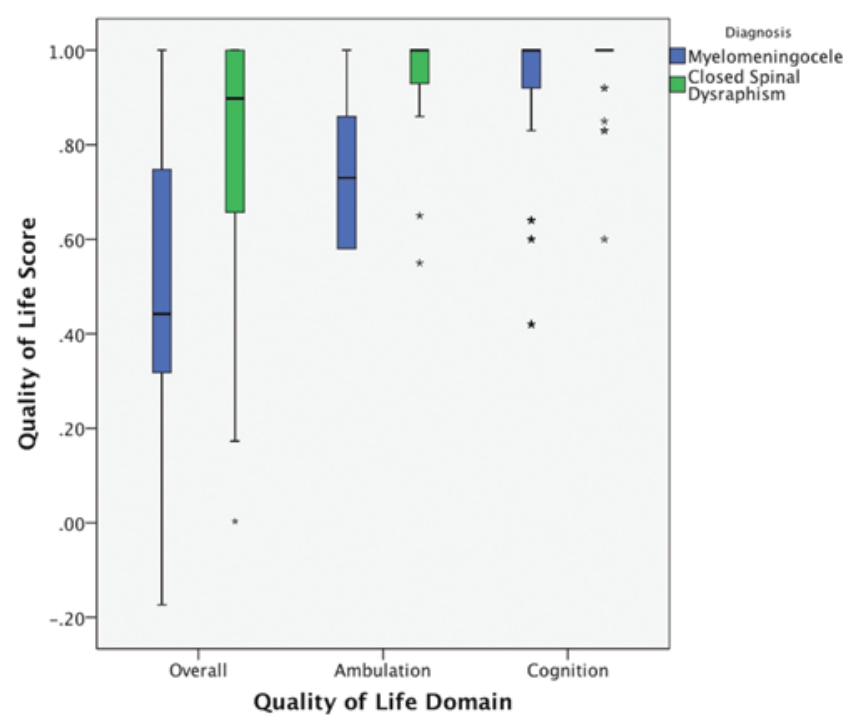

FIG. 1. Overall HRQOL, ambulation, and cognition subscores contrasting myelomeningocele patients with closed spinal dysraphism patients. The solid lines denote the mean; boxes, the interquartile range; bars, range; and asterisks, outliers. Figure is available in color online only. subscore were significantly associated with both bowel continence and bladder continence $(\mathrm{p}<0.05)$. None of the other domains tested showed significant associations. Only the association between overall QOL and bowel continence persisted with control for underlying diagnosis $(\mathrm{p}=$ 0.034, 2-way ANOVA). However, the effect size for bowel continence was small (partial eta squared $=0.03$; Fig. 2 ).

\section{Myelomeningocele Patients}

To evaluate the impact of the presence of a ventriculoperitoneal (VP) shunt, history of CM-II decompression, history of tethered cord release, and ambulation ability on QOL, we considered only those patients with myelomeningocele. No patient with closed spinal dysraphism had a history of shunt placement or CM-II decompression, and only 1 patient (with lipomyelomeningocele) was not able to ambulate in the community.

One hundred six patients (85\%) had a history of CSF shunting. These patients had lower overall QOL scores compared with patients without a history of shunting $(0.47$ vs $0.74, p<0.001)$. Scores for ambulation and cognition were also lower in shunt-treated patients $(0.91$ vs 0.98 for cognition, $\mathrm{p}=0.17 ; 0.72$ vs 0.87 for ambulation, $\mathrm{p}=0.002$; Fig. 3). The effect of shunting on these 3 QOL scores remained significant when we controlled for age as a potential confounding variable, with shunt status accounting for $10.5 \%$ of the variability in overall QOL score. Patients with shunts underwent a median of 2 shunt revisions (range 0-18). Considering the number of shunt revisions as a continuous variable, we observed weak correlations between shunt revision and overall QOL (Spearman rho = $-0.197, p=0.048$ ) and several subscores (vision, speech, and ambulation, all $\mathrm{p}$ values between 0.01 and 0.05 ). We found similar associations when comparing patients with 0 or 1 shunt revision to those with 2 or more shunt revisions (higher vision, speech, ambulation, and overall QOL were associated with fewer shunt revisions; all $\mathrm{p}$ values between 0.005 and 0.05 ). When we corrected for multiple measures, only the association of history of shunt treatment with overall QOL and ambulation remain significant.

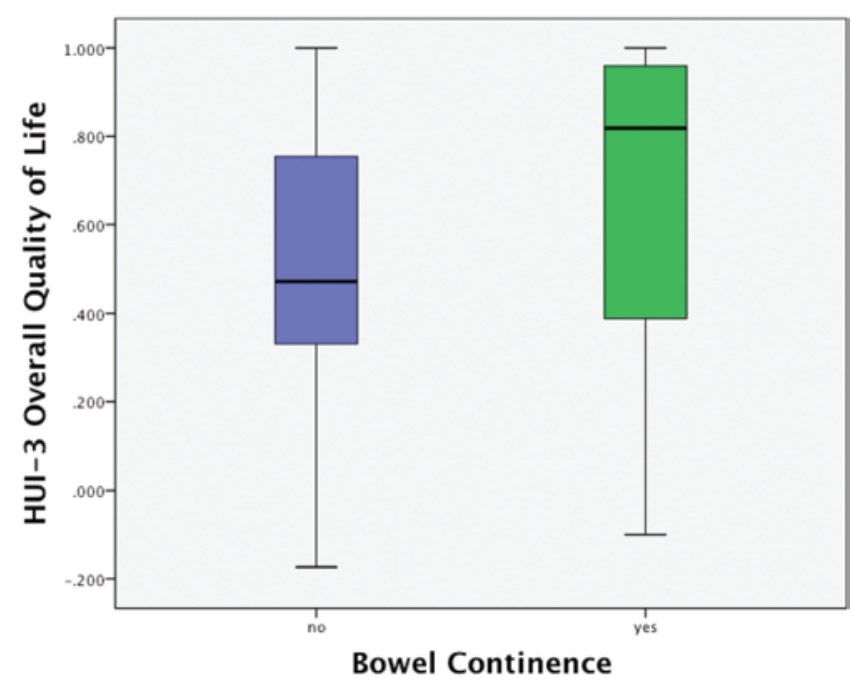

FIG. 2. Overall QOL comparing patients with normal bowel continence to those with incontinence. Figure is available in color online only. 


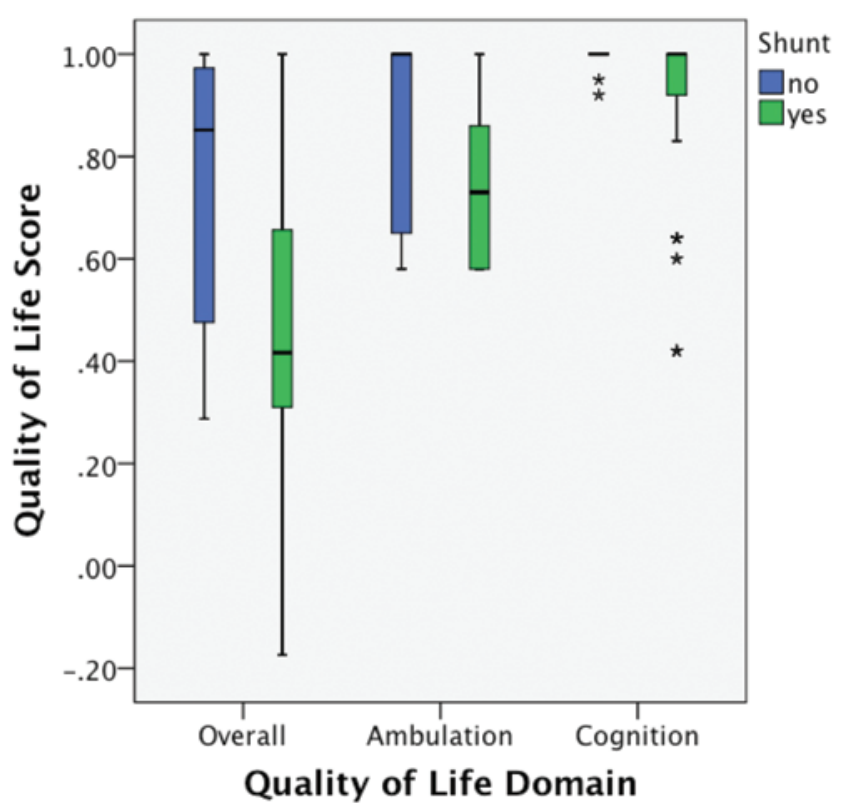

FIG. 3. Overall HRQOL, ambulation, and cognition subscores of myelomeningocele patients, comparing those with a history of CSF shunting to those without. Figure is available in color online only.

Fourteen patients (11\%) had undergone CM-II decompression. These patients had lower overall QOL scores than patients without a history of CM-II decompression (0.29 vs $0.53, \mathrm{p}=0.005$; Fig. 4). The association of CM-II decompression with lower overall QOL persisted when we controlled for age. When both CM-II decompression and shunting were considered, history of either procedure had an independent, statistically significant negative effect on overall QOL. The mean overall QOL score for patients without a history of shunt treatment or Chiari decompression was 0.74; with history of shunt but no Chiari decompression the score was 0.49 ; and with history of both shunt and Chiari decompression it was 0.29 . Scores for speech

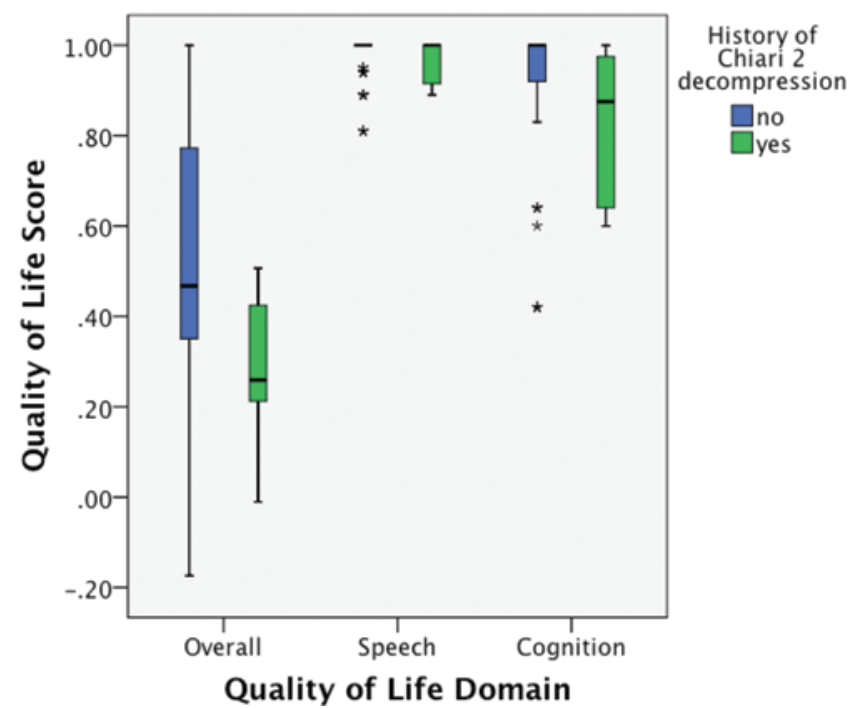

FIG. 4. Overall HRQOL, speech, and cognition subscores of myelomeningocele patients comparing those with history of CM-II decompression to those without. Figure is available in color online only. and cognition were also significantly lower in patients who had undergone Chiari decompression (speech 0.96 vs 0.99 , $\mathrm{p}=0.011$; cognition 0.83 vs $0.93, \mathrm{p}=0.005)$.

Thirty-seven patients $(30 \%)$ had a history of tethered cord release. These patients had lower pain-related QOL scores than patients who had not undergone tethered cord release $(0.95$ vs $0.98, \mathrm{p}=0.004)$. Neither overall QOL nor any other component differed in patients with compared with those without a history of tethered cord.

As expected, ambulation ability_defined as 1) ability to ambulate in the community; 2) ability to ambulate in the household; 3) ability to ambulate minimally, with no functional ambulation; or 4) nonambulatory-was associated with the QOL ambulation subscore. There was also a statistically significant association with overall QOL, but this association was not significant when we controlled for ambulation subscore. In other words, all of the variance in overall QOL observed with comparison of patients' ability to ambulate is accounted for by the difference in ambulation subscore. We attempted to control for ambulation ability when assessing the effect of shunt treatment and Chiari decompression on QOL. However, there were too few subjects in each ambulation category without shunts or with Chiari decompression to satisfactorily perform this analysis.

\section{Discussion}

\section{Effect of Underlying Diagnosis}

We have performed an HRQOL survey on children attending a multidisciplinary spina bifida clinic. Several interesting observations can be made based on these data. Primarily, in a spina bifida clinic that includes patients with multiple different forms of spinal dysraphism, the largest contributor to HRQOL score is diagnosis. Patients with myelomeningocele have lower HRQOL scores than patients with closed spinal dysraphism. Examination of the 8 domain subscores reveals significantly lower scores in ambulation and cognition in myelomeningocele patients. These differences in ambulation and cognition appear to be the factors that account for the overall HRQOL difference. A lower score in ambulation is not surprising, as patients with myelomeningocele are far more likely to have impaired lower-extremity function than patients with closed defects. Likewise, while it was previously thought that patients with CM-II and spina bifida had normal intelligence, recent investigations have revealed that this population instead has many subtle cognitive deficits compared with a "normal" population. 6,10 Finally, the difference in HRQOL between patients with open and closed spinal dysraphism is consistent with previous reports. ${ }^{24}$

\section{Effect of Demographic Variables}

Many factors have been investigated for possible effects on HRQOL of patients with spina bifida. In studies with children and their caregivers, some researchers have noted that poor HRQOL is clinically related to lesion level, age, ambulatory ability, family function, and rehabilitation treatment team integration.9,12,14,18,20,22,23,25 Meanwhile, other studies have noted that HRQOL in spina bifida patients is unrelated to age, functional ability, lesion level, 
sex, obesity, or sexual function. . $^{1,8,13,14,15,20}$ Our investigation of several variables that were applicable to the entire clinic population found none that correlated with HRQOL score. These variables included whether the survey was completed by patient or caregiver, type of insurance, and patient sex and race. We did find a weak correlation between younger age and better HRQOL score. The present analysis cannot determine whether this correlation between age and HRQOL score represents a loss of function as the patient ages versus a declining perception of health on the part of the patient or caregiver. Further analysis of the effects of aging on spina bifida patients may be warranted to examine this finding.

\section{Bowel and Bladder Control}

We found only weak correlation between HRQOL and bowel function, and no correlation with bladder function when we controlled for the underlying diagnosis. Previous studies of spina bifida patients have had similar difficulties elucidating the importance of bowel and bladder continence. ${ }^{20}$ Quality of life measures that are not spina bifida specific do not include questions about bowel and bladder control and thus are ill suited to examine that aspect of those patients' lives. In the present study, utilizing the HUI3, any effect that bowel or bladder control might have on QOL would be noted only if it produced an effect in 1 of the 8 measured domains. Future development of QOL metrics for use in this population must include specific assessment of bowel and bladder function.

\section{Shunts and CM-II in Myelomeningocele Patients}

Perhaps the most intriguing finding of the present study is the potential relationship between the presence of a VP shunt and poor HRQOL scores. Because no patient with a closed spinal dysraphism had a shunt, we considered only myelomeningocele patients in this analysis. The effect of shunt presence on overall HRQOL score was the most dramatic of any comparison made in the present study (approximately equivalent to the difference between patients with open myelomeningocele and closed spinal dysraphism). This effect persisted with control for age and control for CM-II decompression. In fact, CM-II decompression and shunt presence were nearly additive in their detrimental effect on overall QOL. Increasing numbers of shunt revisions, while weakly associated with worsening overall HRQOL scores, did not retain significance when we controlled for multiple measures. This leaves the presence of a shunt as the main driver of QOL in the myelomeningocele population.

Several previous studies have examined the effect of shunting on QOL in myelomeningocele patients, most of which have found no association. ${ }^{20,21}$ However, Ramachandra et al. recently studied a cohort of 74 patients with myelomeningocele using the PedsQL 4.0 scale and found history of VP shunt to be associated with a significantly lower patient-reported physical health summary score. ${ }^{18}$ Shunting did not have a significant effect on the psychosocial or total health score. Hampton et al. demonstrated that shunt-treated myelomeningocele patients have poorer performance on a number of neuropsychological evalua- tions compared with myelomeningocele patients without hydrocephalus. ${ }^{11}$

One possible explanation for the result observed in the present study is that the presence of a shunt is simply a proxy for greater degree of illness or chronic disease. We do not have the capacity to evaluate or to control for comorbid medical conditions that may affect QOL and occur more often in shunt-treated patients than in non-shunttreated patients. However, it is possible that hydrocephalus that requires shunting does have a negative overall effect on QOL for these patients. Of note, the myelomeningocele patients treated during this time period did not undergo endoscopic third ventriculostomy (ETV) or ETV with choroid plexus cauterization (ETV/CPC). Therefore, no assessment can be made as to whether the shunt itself or the presence of hydrocephalus is associated with the lower HRQOL scores.

As care for these children continues to evolve and some centers advocate more stringent criteria for shunting, accepting some degree of ventriculomegaly, it is essential that we continue to study both QOL and neuropsycho$\operatorname{logical} / \operatorname{cog}$ nitive outcomes for this population of patients. ${ }^{5}$ Furthermore, if ETV/CPC becomes a widely used treatment modality for individuals with hydrocephalus related to spina bifida, it will be important to determine if ETV/ CPC has a similar association with HRQOL as shunting.

\section{Limitations}

This is a survey-based QOL study performed on a population of patients seen at a multidisciplinary spina bifida clinic. We believe that 56\% survey completion represents a satisfactory rate of completion for a survey-based study and a satisfactory sampling of our spina bifida population. However, there are several limitations. The HUI3 is a general QOL metric and is not specific to children or spina bifida. As such, an inordinate amount of weight is given to the ambulation domain. This is likely the primary reason for the difference observed between patients with myelomeningocele and those with closed dysraphism. Ambulatory ability may also play a role in the observed difference in QOL between patients with and without shunts and those who have undergone CM-II decompression, but there are insufficient data to perform this analysis. In addition, there are no questions about bowel or bladder continence, as discussed above, and no assessment of family function or rehabilitation team participation. Other limitations include lack of information about the myelomeningocele level, either anatomical or neurological, and about medical comorbidities.

\section{Conclusions}

We have used a general QOL scale to evaluate patients in the COA multidisciplinary spina bifida clinic. In this group of children with both open and closed spinal dysraphism, open myelomeningocele is associated with lower overall HRQOL. Among myelomeningocele patients, history of hydrocephalus treated with shunting is associated with lower HRQOL. Development of a spina bifida-specific QOL metric would facilitate more accurate study of these patients. Continued study is needed to determine 
how medical and surgical interventions might improve QOL for these patients.

\section{References}

1. Abresch RT, McDonald DA, Widman LM, McGinnis K, Hickey KJ: Impact of spinal cord dysfunction and obesity on the health-related quality of life of children and adolescents. J Spinal Cord Med 30 (Suppl 1):S112-S118, 2007

2. Bol KA, Collins JS, Kirby RS, National Birth Defects Prevention Network: Survival of infants with neural tube defects in the presence of folic acid fortification. Pediatrics 117:803-813, 2006

3. Bowman RM, McLone DG, Grant JA, Tomita T, Ito JA: Spina bifida outcome: a 25-year prospective. Pediatr Neurosurg 34:114-120, 2001

4. Centers for Disease Control and Prevention: Spina bifida and anencephaly before and after folic acid mandate-United States, 1995-1996 and 1999-2000. MMWR Morb Mortal Wkly Rep 53:362-365, 2004

5. Chakraborty A, Crimmins D, Hayward R, Thompson D: Toward reducing shunt placement rates in patients with myelomeningocele. J Neurosurg Pediatr 1:361-365, 2008

6. Dennis M, Barnes MA: The cognitive phenotype of spina bifida meningomyelocele. Dev Disabil Res Rev 16:31-39, 2010

7. Feeny D, Furlong W, Torrance GW, Goldsmith $\mathrm{CH}, \mathrm{Zhu} \mathrm{Z}$, DePauw S, et al: Multiattribute and single-attribute utility functions for the health utilities index mark 3 system. Med Care 40:113-128, 2002

8. Flanagan A, Gorzkowski M, Altiok H, Hassani S, Ahn KW: Activity level, functional health, and quality of life of children with myelomeningocele as perceived by parents. Clin Orthop Relat Res 469:1230-1235, 2011

9. Flanagan A, Kelly EH, Vogel LC: Psychosocial outcomes of children and adolescents with early-onset spinal cord injury and those with spina bifida. Pediatr Phys Ther 25:452-459, 2013

10. Guthkelch AN: Intelligence of children with Chiari malformation type II. Childs Nerv Syst 1:69, 1985 (Letter)

11. Hampton LE, Fletcher JM, Cirino PT, Blaser S, Kramer LA, Drake J, et al: Hydrocephalus status in spina bifida: an evaluation of variations in neuropsychological outcomes. Clinical article. J Neurosurg Pediatr 8:289-298, 2011

12. Kulkarni AV, Cochrane DD, McNeely PD, Shams I: Medical, social, and economic factors associated with health-related quality of life in Canadian children with hydrocephalus. J Pediatr 153:689-695, 2008

13. Lassmann J, Garibay Gonzalez F, Melchionni JB, Pasquariello PS Jr, Snyder HM III: Sexual function in adult patients with spina bifida and its impact on quality of life. J Urol 178:1611-1614, 2007

14. Oddson BE, Clancy CA, McGrath PJ: The role of pain in reduced quality of life and depressive symptomology in children with spina bifida. Clin J Pain 22:784-789, 2006

15. Okurowska-Zawada B, Kułak W, Otapowicz D, Sienkiewicz D, Paszko-Patej G, Wojtkowski J: Quality of life in children and adolescents with cerebral palsy and myelomeningocele. Pediatr Neurol 45:163-168, 2011

16. Parker SE, Mai CT, Canfield MA, Rickard R, Wang Y, Meyer
RE, et al: Updated national birth prevalence estimates for selected birth defects in the United States, 2004-2006. Birth Defects Res A Clin Mol Teratol 88:1008-1016, 2010

17. Parkin PC, Kirpalani HM, Rosenbaum PL, Fehlings DL, Van Nie A, Willan AR, et al: Development of a health-related quality of life instrument for use in children with spina bifida. Qual Life Res 6:123-132, 1997

18. Ramachandra P, Palazzi KL, Skalsky AJ, Marietti S, Chiang G: Shunted hydrocephalus has a significant impact on quality of life in children with spina bifida. PM R 5:825-831, 2013

19. Sandler AD: Children with spina bifida: key clinical issues. Pediatr Clin North Am 57:879-892, 2010

20. Sawin KJ, Bellin MH: Quality of life in individuals with spina bifida: a research update. Dev Disabil Res Rev 16:47-59, 2010

21. Sawin KJ, Brei TJ, Buran CF, Fastenau PS: Factors associated with quality of life in adolescents with spina bifida. J Holist Nurs 20:279-304, 2002

22. Thurston S, Paul L, Ye C, Loney P, Browne D, Browne G, et al: System integration and its influence on the quality of life of children with complex needs. Int J Pediatr 2010:570209, 2010

23. Tilford JM, Grosse SD, Robbins JM, Pyne JM, Cleves MA, Hobbs CA: Health state preference scores of children with spina bifida and their caregivers. Qual Life Res 14:10871098, 2005

24. Wang JC, Lai CJ, Wong TT, Liang ML, Chen HH, Chan $\mathrm{RC}$, et al: Health-related quality of life in children and adolescents with spinal dysraphism: results from a Taiwanese sample. Childs Nerv Syst 29:1671-1679, 2013

25. Young NL, Sheridan K, Burke TA, Mukherjee S, McCormick A: Health outcomes among youths and adults with spina bifida. J Pediatr 162:993-998, 2013

\section{Author Contributions}

Conception and design: Boddiford, Shannon, Blount. Acquisition of data: Bishop, Scogin, Hopson, Arynchyna, Boddiford, Shannon. Analysis and interpretation of data: Rocque, Hopson, Arynchyna, Shannon. Drafting the article: Rocque, Scogin, Shannon. Critically revising the article: Rocque, Bishop, Scogin, Hopson, Shannon, Blount. Reviewed submitted version of manuscript: Rocque, Bishop, Scogin, Hopson, Arynchyna, Shannon, Blount. Approved the final version of the manuscript on behalf of all authors: Rocque. Statistical analysis: Rocque, Shannon. Administrative/technical/material support: Bishop, Hopson, Arynchyna. Study supervision: Blount.

\section{Supplemental Information \\ Previous Presentation}

This work was presented at the 42nd Annual Meeting of the AANS/CNS Section on Pediatric Neurological Surgery, held in Toronto, ON, Canada, on December 3-6, 2013.

\section{Correspondence}

Brandon G. Rocque, Pediatric Neurosurgery, Department of Neurosurgery, University of Alabama at Birmingham, 1600 Seventh Ave. S., Lowder 400, Birmingham, AL 35233. email: brandon.rocque@childrensal.org. 